\title{
$\mathrm{Mn}_{1.29} \mathrm{Fe}_{1.11} \mathrm{O}_{4}$ フェライトの焼結と磁気特性に およぼす弗化物の添加効果
}

\author{
雨 宮 政 博 \\ （株）日立製作所 中央研究所）
}

\section{Effects of Fluoride Addition on Sintering and Magnetic Properties of $\mathrm{Mn}_{1.29} \mathrm{Fe}_{1.71} \mathrm{O}_{4}$ Ferrite}

\author{
By \\ Masahiro AMEMIYA \\ (Central Research Laboratory, Hitachi, Ltd.)
}

\begin{abstract}
Effects of addition of fluorides, $\mathrm{MnF}_{2}$ and $\mathrm{FeF}_{3} \cdot 3 \mathrm{H}_{2} \mathrm{O}$, on the sintering of $\mathrm{Mn}_{1.29} \mathrm{Fe}_{1.71} \mathrm{O}_{4}$ ferrite compact and magnetic properties of the fired ferrite body were studied by measuring the fired bulk density, grain size, B-H curve(magnetic hysteresis curve), ferrimagnetic Curie temperature, saturation magnetization and crystal lattice constant. The results obtained are as follows.

1) By addition of the fluorides, grain size and bulk density of the fired ferrite body became larger.

2) No fluorine was contained in the fired ferrite body, since all the amount of fluorine had been liberated during the firing.

3) No ferrimagnetic Curie temperature, saturation magnetization and crystal lattice constant being intrinsic properties of ferrite were changed with addition of the fluorides.

4) By addition of the fluorides, magnetic hysteresis characteristics depending on the compactness of the ferrite materials were changed, i.e., magnetic flux density became larger and coercive force became smaller.
\end{abstract}

[Received November 1, 1973]

\section{1. 緒言}

フェライトは，記憶素子，搬送用コア，磁気ヘッドな どとして電子工学分野で広く使われている磁性材料であ る.これらの各用途には, 一部, 単結晶フェライトが用 いられているが，通常は多結晶からなる焼結フェライト が用いられている.

焼結フェライトにおいては，材質組成が同一でも，い わゆる燒結体としての性質一焼結体密度, 結晶粒の大き さ・形状，空孔の分布状態など一によって磁気特性が大 きく左右される.このため, 焼結体としての性質を望ま しい方向に改善するための種々な研究がなされてきてお り，その1つに，フェライト製造原料にある種の物質 （添加剤と称している）を少量添加して焼成する方法が ある ${ }^{1)}$.

本研究も，上記のような目的をもってなされたもの で, フェライトの焼結におよぼす弗化物の添加効果につ いて検討したものである.

さて，弗化物をフェライト製造原料の一部として用い ることはすでに，小林ら ${ }^{2)}$ な) な゙によって試みられてい
る。その報告には，弗化物を原料の一部として用いる と, フェライトの酸素イオンの一部が弗素イオンで置換 されること, さらに, 弗素イオン置換によって磁気特性 が向上すること，などが述べられている．しかし，弗化 物のフェライトの燒結におよぼす効果について扱った報 告はほとんど見当たらない。

本報告では, $\mathrm{Mn}_{1.29} \mathrm{Fe}_{1.71} \mathrm{O}_{4}$ フェライトを用いて，フ エライト製造原料への弗化物, $\mathrm{MnF}_{2}$ と $\mathrm{FeF}_{3} \cdot 3 \mathrm{H}_{2} \mathrm{O}$,の 添加がフェライトの焼結体としての性質にどのような影 響をおよぼすか, また，燒結体としての性質の変化が磁 気特性にどのような影響を与えるかを調べた，以下にそ の詳細を実験結果を主体に報告する。

\section{2. 実験}

$\mathrm{Mn}_{1,29} \mathrm{Fe}_{1.71} \mathrm{O}_{4}$ フェライトの焼結ならびに磁気特性に およぼす弗化物の添加効果の検討は，弗化物を添加して 焼成したフェライト焼結体の焼結体密度, 結晶粒径, B - $\mathrm{H}$ 曲線 (磁気履歴曲線), キュリー温度, 飽和磁化, 結晶格子定数を測定することによって行なった. 用いた 
弗化物は $\mathrm{MnF}_{2}$ 亡 $\mathrm{FeF}_{3} \cdot 3 \mathrm{H}_{2} \mathrm{O}$ であるが, 双方の添加 剂としての効果は泳ぼ同じであったので, 本報告では主 として $\mathrm{MnF}_{2}$ を用いた場合について示す.

\section{1 实験試料の調製}

$\mathrm{MnCO}_{3}$ と $\alpha-\mathrm{Fe}_{2} \mathrm{O}_{3}$ を製造原料として用いて, 実験 試料を調製した。

まず，弗化物の添加方法について述べると次のよう で，フェライト製造原料混合物中の鉄とマンガンの比率 が，弗化物を添加しても変わらないようにした． $\mathrm{MnF}_{2}$ を添加する場合は，

$$
\begin{aligned}
\mathrm{MnCO}_{3} & : 60-x \text { mol} \% \\
\mathrm{MnF}_{2} & : x \\
\mathrm{Fe}_{2} \mathrm{O}_{3} & : 40
\end{aligned}
$$

であり， $x$ を0 20 の籁囲で変化させた。 $\mathrm{FeF}_{3} \cdot 3 \mathrm{H}_{2} \mathrm{O}$ を添加する場合は，

$\mathrm{MnCO}_{3}: 60 \mathrm{~mol} \%$

$$
\mathrm{Fe}_{2} \mathrm{O}_{3}: 40-\frac{1}{2} x
$$

$\mathrm{FeF}_{3} \cdot 3 \mathrm{H}_{2} \mathrm{O}: x$

であり， $x$ を 20 の範囲で変化させた。

つぎに，試料の調整方法について述べる，上記組成と なるよう秤量した原料を擂潰機で 3 時間混合した。この 混合物它 $900^{\circ} \mathrm{C}$ で 1 時間仮焼成し，仮焼成後擂潰機で 4 時間粉挽しそ.これにバインダーとしてポリビニルア ルコール $1.5 \mathrm{wt} \%$ を添加し，顆粒となした。この顆粒 を用いて，トロイドとペレットを $2 \sim 2.5 \mathrm{t} / \mathrm{cm}^{2}$ の圧力 で加圧成形した。 そして, 成形体を弗化物の融点以上と 思わ礼る*1070 〜 $1300^{\circ} \mathrm{C}$ で 2 11 時間本焼成した.な お，仮焼成，本焼成とも，焼成温度までの昇温時間は 3 時間とし，焼成雾囲気には空気究用いた。焼成後は室温 にとりだし放冷した。

\section{2 焼結体密度亡結晶粒径の測定}

焼結体密度は，焼結体の寸法と重量を精密に測定し， その測定値から計算した。測定には， $10 \mathrm{~mm} \phi \times 5 \mathrm{~mm}$ の ペレット試料を用いた。結晶粒径は次のようにして求め た。上記ペレット試料を破砕し，破面を平らになるまで 研磨してから熱塩酸でエッチングし, その面の顕微 鏡写真を撮影した.この顕微鏡写真を用いて，一定 面積内にある結晶粒の数をかぞえ，1つの結晶粒の 占为る平均の面積をだした，そして，これと同一の 面積を有する円の直径を求め, その值をもって粒径 とした。

\subsection{B-H 特性の測定}

安藤電気製の交流磁化特性測定装置を用いて, 磁 場 $12.5 \mathrm{Oe}$ ，周波数 $50 \mathrm{~Hz}$ において B-H 曲線を測定 した。この B-H 曲線から B-H 特性, つまり最大

* $\mathrm{MnF}_{2}$ の融点は $856^{\circ} \mathrm{C}$ である7). 鉄の弗化物, $\mathrm{FeF}_{2}$ と $\mathrm{FeF}_{3}$, の融点はあ⿱り明確ではなく, > $1000^{\circ} \mathrm{C}$ と 報告りされている
磁束密度 $B_{m}$, 残留磁束密度 $B_{r}$ および保磁力 $H_{c}$ を求 めた. 測定には, 内径 $17 \mathrm{~mm} \phi$, 外径 $26 \mathrm{~mm} \phi$, 高さ 4.5 $\mathrm{mm}$ のトロイド試料学用いた。

\section{4 キュリー温度と飽和磁化の測定}

測定器には自動記録磁気天秤を，標準試料にはニッケ ルを用いて，キュリ一温度と室温における飽和磁化を測 定した。測定磁場は 2000 Oe で，測定試料には 2.2 項 あるいは 2.3 項の成形試料を粉砕し，粉末としたものを 用いた。

\section{5 結晶格子定数の測定と生成相の同定}

装置には理学電機製の自動記録X線回折装置を，X線 源には $\mathrm{Fe} \mathrm{K}_{\alpha}$ 線を用い，(440) 面および $(511,333)$ 面からの回折角を測定し，この回折角の值から結晶格子 定数を求めた。本実験に晾いては，珪素を標準試料とし て用いて，回折角の補正を行なった。

生成相の同定は， $2 \theta$ で $20^{\circ} \sim 90^{\circ}$ の範囲の回折線に よって行なった。

\section{6 弗素, 鉄およびマンガンの定量分析}

一部の試料に関して, 弗素, 鉄扔よびマンガンの定量 分析を行なった. 弗素の定量は, La-アリザリンコンプ レックソン錯体を発色試楽とする吸光光度法 ${ }^{51,6)}$ によ。 て, また, 鉄とマンガンの定量は, 蛍光X線法によっ て，それぞれ行なった。

\section{1 焼結体密度と結晶粒径}

$\mathrm{MnF}_{2}$ を添加した場合についての結果を示す.

図-1 は，焼成温度をパラメータにし， $\mathrm{MnF}_{2}$ の添加 量に対する焼結体密度の変化を示したものである. 図か らわかるように， $\mathrm{MnF}_{2}$ を添加すると，その添加量が $12 \mathrm{~mol} \%$ までは燒結体密度が大幅に向上する。しかし， 添加量が $15 \mathrm{~mol} \%$ をこえると, 逆に燒結体密度は低下 する.

図-2 は，焼成温度を $1170^{\circ} \mathrm{C}$ と一定にしたときの，焼 結体密度の焼成時間依存性を示したものである. $\mathrm{MnF}_{2}$

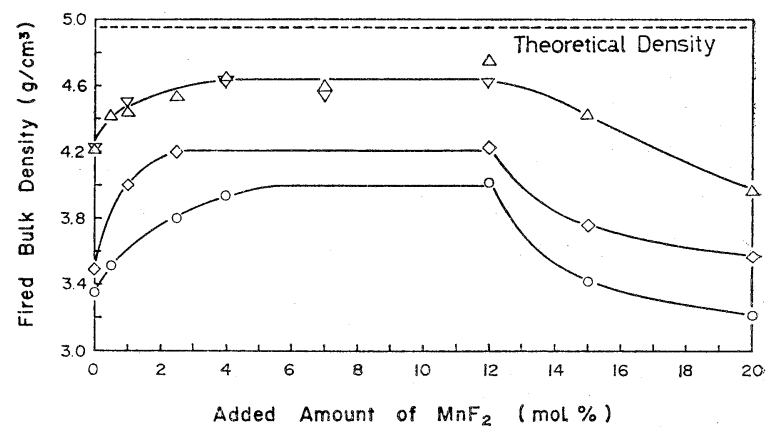

firing temperature : $-\mathrm{O}: 1070^{\circ} \mathrm{C}, \diamond: 1150^{\circ} \mathrm{C}, \nabla: 1200^{\circ} \mathrm{C}, \triangle: 1250^{\circ} \mathrm{C}$

Fig. 1. Changes in fired bulk density with added amount of $\mathrm{MnF}_{2}$ for the compacts fired for $2 \mathrm{~h}$. 


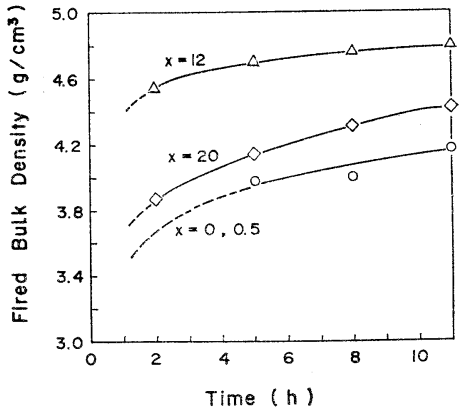

Fig. 2. Changes in fired bulk density with firing time for the compacts fired at $1170^{\circ} \mathrm{C} . x$ represents the amount of $\mathrm{MnF}_{2}$ in $\mathrm{mol} \%$ added before firing.

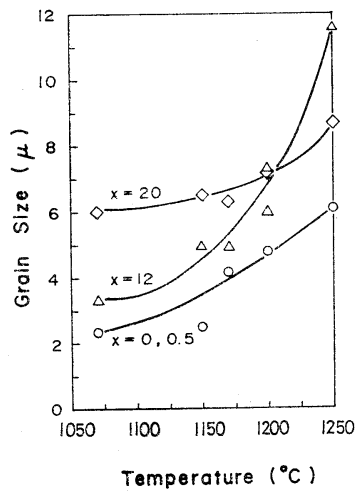

Fig. 3. Changes in grain size with firing temperature for the compacts fired for $2 \mathrm{~h}$. $x$ represents the amount of $\mathrm{MnF}_{2}$ in $\mathrm{mol} \%$ added before firing.

の添加量が 0 あるい性 $0.5 \mathrm{~mol} \%, 12 \mathrm{~mol} \%$ ，扩よび $20 \mathrm{~mol} \%$ の場合について示した。図からわかるように， $\mathrm{MnF}_{2}$ を $12 \mathrm{~mol} \%$ 添加したものは, 他のものに比心゙,短 時間の焼成で焼結密度が焼成温度の飽和值に近づく。

図-3，4 は，図-2 と同し $\mathrm{MnF}_{2}$ の添加量の試料に関 して, 結晶粒径と焼成温度・時間との関係を示したもの である、図からわかるように, $\mathrm{MnF}_{2}$ 索添加すると, 結 晶粒も大きくなる。

図-5 は, 以上述べた焼結体密度と結晶粒径との関係 を, 図-2 と同じ $\mathrm{MnF}_{2}$ の添加量の試料に関して示した ものである。図からわかるように, $\mathrm{MnF}_{2}$ を添加すると， 焼結体密度と結晶粒径との関係が変化する. $\mathrm{MnF}_{2}$ を $12 \mathrm{~mol} \%$ 加えたものでは，同じ結晶粒径で焼結体密度 を比較すると, 焼結体密度が大きくなっている.

$\mathrm{FeF}_{3} \cdot 3 \mathrm{H}_{2} \mathrm{O}$ を添加した場合も, $\mathrm{MnF}_{2}$ の場合とほぼ 同様な結果が得られた。すなわち, $\mathrm{FeF}_{3} \cdot 3 \mathrm{H}_{2} \mathrm{O}$ を添加 すると, 添加量が $10 \mathrm{~mol} \%$ までは, 焼結体密度が向上 する.しかし, 添加量が $14 \mathrm{~mol} \%$ をこえると, 逆に燒 結体密度は低下する. $\mathrm{FeF}_{3} \cdot 3 \mathrm{H}_{2} \mathrm{O}$ の添加は, また, 結 晶粒を大きくする効果をもつ.

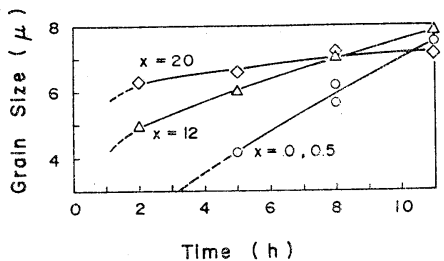

Fig. 4. Changes in grain size with firing time for the compacts fired at $1170^{\circ} \mathrm{C} . x$ represents the amount of $\mathrm{MnF}_{2}$ in mol\% added before fring.

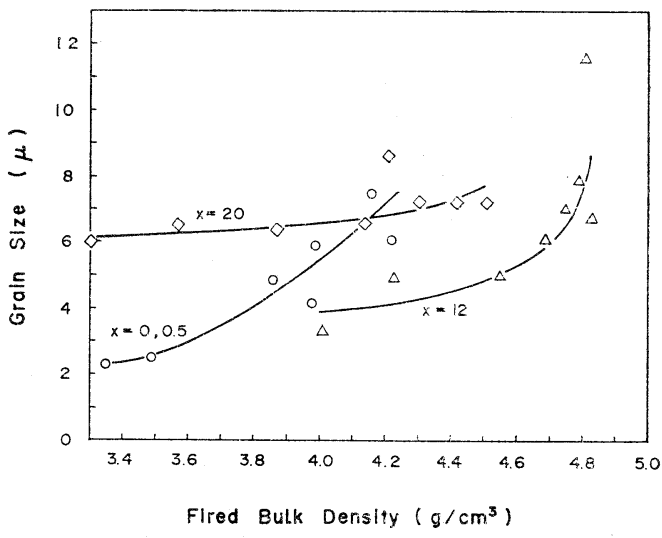

Fig. 5. Relation between grain size and fired bulk density for compacts fired under various conditions. $x$ represents the amount of $\mathrm{MnF}_{2}$ in mol\% added before firing.

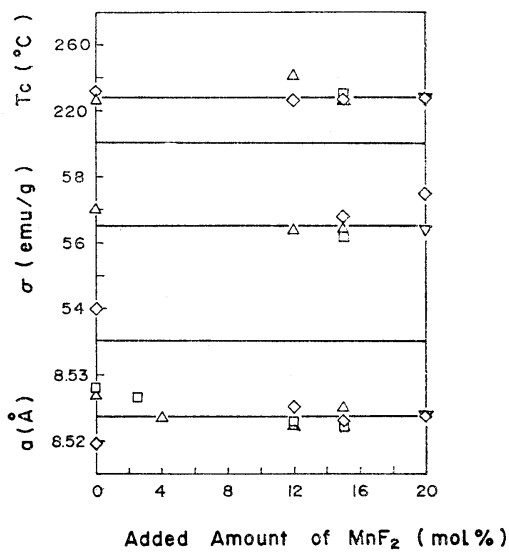

firing temperature : $-\diamond: 1070^{\circ} \mathrm{C}, \nabla: 1170^{\circ} \mathrm{C}, \square: 1200^{\circ} \mathrm{C}$, $\mathrm{O}: 1250^{\circ} \mathrm{C}, \triangle: 1300^{\circ} \mathrm{C}$

Fig. 6. Ferrimagnetic Curie temperature, saturation magnetization and crystal lattice constant vs. added amount of $\mathrm{MnF}_{2}$ for the compacts fired for $2 \mathrm{~h}$.

\section{2 キュリー温度, 飽和磁化および結晶格子定数} $\mathrm{MnF}_{2}$ を添加した場合についての 測定結果を図一6 に 示寸. 図から, 弗化物党添加しても, フェライトの intrinsic な性翼であるキュリー温度, 飽和磁化および結晶 
格子定数は変わらないことがわかった。

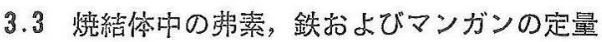

$\mathrm{MnF}_{2}$ を $20 \mathrm{~mol} \%$ 加え, $1070^{\circ} \mathrm{C}$ で 2 時間焼成した 試料と, $\mathrm{FeF}_{3} \cdot 3 \mathrm{H}_{2} \mathrm{O}$ を $5 \mathrm{~mol} \%$ 加え, $1100^{\circ} \mathrm{C}$ で 2 時閒 焼成した試料に関して,弗素の定量分析走行なったが,検 出限界（0.005 wt％）以下であった。このことから，弗 素は焼成過程ですべて揮散してしまうことがわかった。

つぎに，上記 2 試料と，弗化物を添加せずに $1070^{\circ} \mathrm{C}$ で 2 時間焼成した試料に関して，鉄とマンガンの定量分

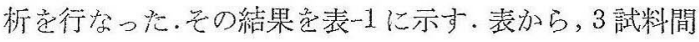
で銑とマンガンの比率に有意差のないことがわかった。 この箺駼結果と, $\mathrm{MnF}_{2}$ 老监独で空気中において, 1100 ${ }^{\circ} \mathrm{C}$ に加熱すると $\mathrm{Mn}_{3} \mathrm{O}_{4}$ になることから，弗素の大部 分礼去方く空気中以少量含まれている水蒸気と反応 し，HF の形で揮散したものと思われる。

Table 1. The results of the quantitative analysis of iron and manganese in the fired ferrite compacts.

\begin{tabular}{cccccc}
\hline No. & $\begin{array}{c}\text { Added amount of } \mathrm{MnF}_{2} \\
\text { or } \mathrm{FeF}_{3} \cdot 3 \mathrm{H}_{2} \mathrm{O}\end{array}$ & $\begin{array}{c}\text { Firing condi- } \\
(\text { mol } \%)\end{array}$ & $\begin{array}{c}\mathrm{Mn} \\
\text { tions }\end{array}$ & $\begin{array}{c}\mathrm{Fe} \\
(\mathrm{wt} \%)\end{array}$ \\
\hline 1 & $\mathrm{MnF}_{2}$ & 20 & $1070^{\circ} \mathrm{C} \times 2 \mathrm{~h}$ & 30 & 41 \\
2 & $\mathrm{FeF}_{3} \cdot 3 \mathrm{H}_{2} \mathrm{O}$ & 5 & $1100^{\circ} \mathrm{C} \times 2 \mathrm{~h}$ & 31 & 41 \\
3 & & 0 & $1070^{\circ} \mathrm{C} \times 2 \mathrm{~h}$ & 30 & 40 \\
\hline
\end{tabular}

\section{$3.4 \mathrm{~B}-\mathrm{H}$ 特性}

3.4 .1 結果 図-7 に, $\mathrm{MnF}_{2}$ の添加量による $\mathrm{B}-$ $\mathrm{H}$ 曲線の変化を示す。また，図-8には，この B-H 曲 線から求めた最大磁束密度 $B_{m}$, 残留磁束密度 $B_{r}$ およ び保磁力 $H_{c}$ 走示す。図-7,8 からわかるよらに, $\mathrm{MnF}_{2}$ を添加すると，添加量が $12 \mathrm{~mol} \%$ までは，B-H 曲線 の角烈性は向上し， $B_{m}$ と $B_{r}$ は大きくなり， $H_{c}$ は小

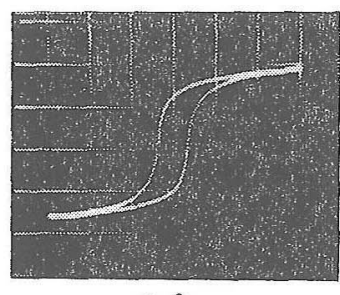

$x=0$

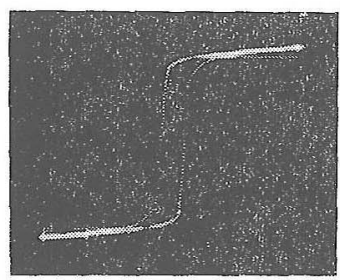

$x=12$

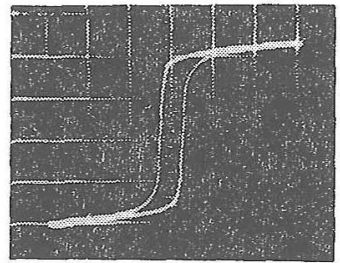

$x=1$

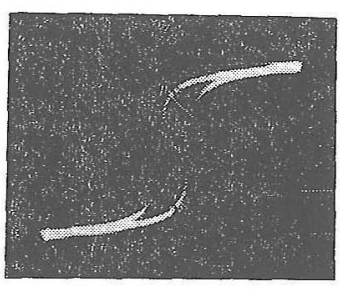

$x=15$
$B=1.2 \mathrm{kG} / \mathrm{div}, H=4.1 \mathrm{Oe} / \mathrm{div}$

Fig. 7. Changes in $\mathrm{B}-\mathrm{H}$ (magnetic hysteresis) curve with addition of $\mathrm{MnF}_{2}$ for the compacts fired for $2 \mathrm{~h}$ at $1300^{\circ} \mathrm{C}$. $x$ represents the amount of $\mathrm{MnF}_{2}$ in mol\% added before firing.

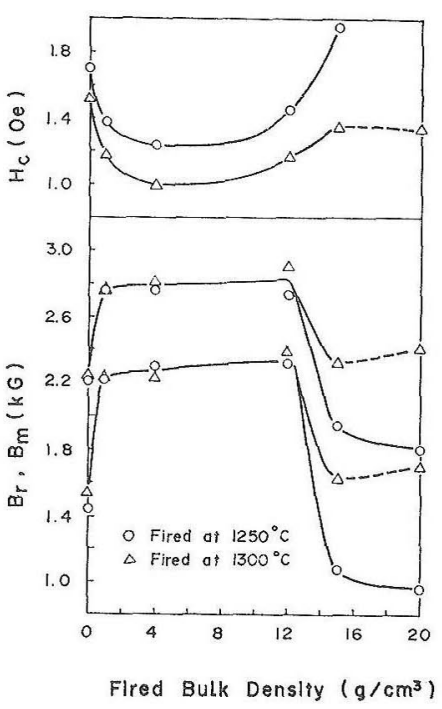

Fig. 8. Relation between B-H characteristics and added amount of $\mathrm{MnF}_{2}$ for the compacts fired for $2 \mathrm{~h}$ at $1250^{\circ}$ and $1300^{\circ} \mathrm{C}$.

さくなる。しかし，添加量が $15 \mathrm{~mol} \%$ 进こえると，逆 に $\mathrm{B}-\mathrm{H}$ 曲線の解型性怯劣化し， $B_{m}$ と $B_{r}$ 注小さくな り， $H_{c}$ は大きくなる.

$\mathrm{FeF}_{3} \cdot 3 \mathrm{H}_{2} \mathrm{O}$ を添加した場合も， $\mathrm{MnF}_{2}$ の場合とほぼ 同様な結果が得られた。すなわち, $\mathrm{FeF}_{3} \cdot 3 \mathrm{H}_{2} \mathrm{O}$ 定添加 すると，添加量が $10 \mathrm{~mol} \%$ まで々， B-H 曲線の解型性 は向上し， $B_{m}$ と $B_{r}$ は大きくなり， $H_{c}$ は小さくなる。 し加し, 添加量分 $14 \mathrm{~mol} \%$ 起こえると, 逆に $\mathrm{B}-\mathrm{H}$ 曲 線の角型性法劣化し， $B_{m}$ と $B_{r}$ は小さくなり, $H_{c}$ は 大きくなる.

3.4 .2 考察 3.2 項から, 弗化物を添加しても物 睤气のものの性質は変わらないことがわかった。したが って,弗化物の添加によ。て起こる B-H 特性の変化洁, 焼結体としての性質の変化による，なかでも $B_{m}$ は，焼 結体密度 $d$ と次の関係にある。

$$
B_{m}=4 \pi \sigma d+H_{a}
$$

ここに, $B_{m}$ は磁束密度 $(\mathrm{G}), \sigma$ 性飽和磁化 $(\mathrm{emu} / \mathrm{g})$, $d$ は焼結体密度 $\left(\mathrm{g} / \mathrm{cm}^{3}\right), H_{a}$ は印加（測定）磁場 $(\mathrm{G})$ である. (1) 式办ら， $B_{m}$ は $\sigma$ 多一定であるので，焼 結体密度 $d$ に比例して增減することが期待される。 お，(1) 式の有辺第 2 項は第 1 項の $1 \%$ 程度以下と小さ く，無視できる。

図-9 は， $B_{m}$ 之焼結体密度との本実験で得られた関 係を示したものである。この図には，広い範国の寒験デ 一夕をうるため，成形圧力を変えて調製した圾料の測定 值も一部含まれている。生た，燒結体密度が理論密度に あるときの，つまり空孔がないときの $B_{m}$ の值も示して おいた，このときの理論密度にはX線密度を用いた。ま た， $B_{m}$ には，3.2 項で示した $2000 \mathrm{Oe}$ の磁場中で測定 


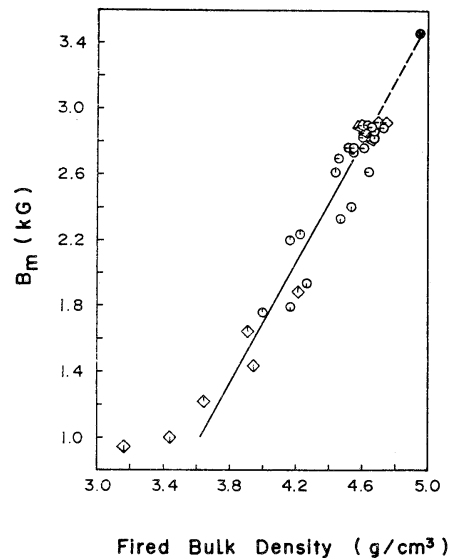

c $x=0 \sim 0.5$ composition of starting materials in mol\%:

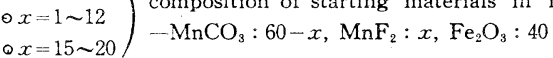
$\diamond x=0 \sim 0.6$ composition of starting materials in $\mathrm{mol} \%$ : $\diamond x=2 \sim 10 \quad-\mathrm{MnCO}_{3}: 60, \mathrm{Fe}_{2} \mathrm{O}_{3}: 40-(1 / 2) x, \mathrm{FeF}_{3} \cdot 3 \mathrm{H}_{2} \mathrm{O}$ $\diamond x=14 \sim 20): x$

- Calculated magnetic flux density for the compact of which fired bulk density is $4.94 \mathrm{~g} / \mathrm{cm}^{3}$ (pore free).

Fig. 9. Relation between magnetic flux density $\left(B_{m}\right)$ and fired bulk density for compacts fired under various conditions.

した飽和磁化 $\sigma$ を使って（1）式から計算した值を用い た。図から， $B_{m}$ はほぼ焼結体密度のみに依存している ことがわかった．ただ，実験で得られた $B_{m}$ と焼結体密 度との近似直線を外插すると，(1) 式から期待される $(B=0, d=0)$ 付近を通らず， $(B=0, d=3)$ 上を通る. つまり，実験で得られた $B_{m}$ の焼結体密度依存性は，

(1) 式から期待されるそれより大きい。これは, 焼結体

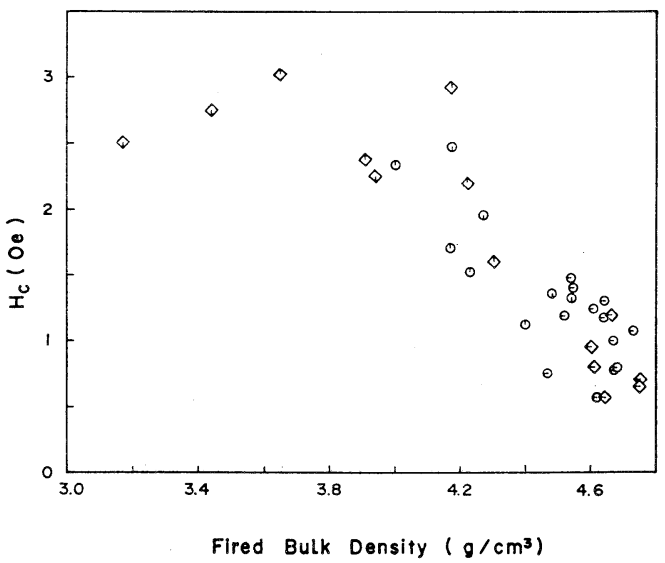

$0 x=0 \sim 0.5$ composition of starting materials in mol\%:

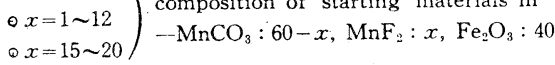
$\diamond x=0 \sim 0.6$ composition of starting materials in mol $\%$ : $\diamond x=2 \sim 10)-\mathrm{MnCO}_{3}: 60, \mathrm{Fe}_{2} \mathrm{O}_{3}: 40-(1 ; 2) x, \mathrm{FeF}_{3} \cdot 3 \mathrm{H}_{2} \mathrm{O}$ $\diamond x=14 \sim 20): x$

Fig. 10. Relation between coercive force $\left(H_{c}\right)$ and fired bulk density for compacts fired under various conditions.
密度が小さくなると，一般に $H_{c}$ が大きくなる（図-10 参照) ため， $12.5 \mathrm{Oe}$ の磁場では試料を十分には磁化し えなくなることによると思われる． $B_{r}$ む $B_{m}$ とほぼ同 様な傾向にあるたただし，燒結体密度が小さくなると， $\mathrm{B}-\mathrm{H}$ 曲線の角型比 $\left(B_{r} / B_{m}\right)$ が低下するので, $B_{m}$ よりも 焼結体密度に対する依存性はさらに大きくなっている。

図-10 は， $H_{c}$ と焼結体密度との関係を示したもので ある、図からわかるように，焼結体密度が大きくなる と, $H_{c}$ は減少する傾向にある.

以上述べたように，弗化物添加による B-H 特性の変 化は,主として焼結体密度の変化によることがわかった。

\section{4. 総括}

$\mathrm{Mn}_{1.29} \mathrm{Fe}_{1.71} \mathrm{O}_{4}$ フェライトの焼結，ならびに磁気特性 におよぼす弗化物, $\mathrm{MnF}_{2}$ と $\mathrm{FeF}_{3} \cdot 3 \mathrm{H}_{2} \mathrm{O}$, の添加効果を 検討した。得られた結果を要約すると,次のようである.

1）弗化物を添加すると，フェライト焼結体の結晶粒 と焼結体密度が大きくなる。

2）弗化物を添加しても，弗素は焼成過程ですべて揮 散してしまい，フェライトの酸素位置の弗素による置換 は起こらなかった。また，フェライトの intrinsic な性 質であるキュリ一温度，飽和磁化および結晶格子定数に も変化はみられなかった。

3）弗化物を添加すると，フェライト焼結体の B-H 特性が変化する. B-H 特性のうち， $B_{m}$ と $B_{r}$ は大き くなり, $H_{c}$ は小さくなる.これは, 弗化物の添加によ って緻密なフェライト焼結体が得られたことによる。

本研究によって, 弗化物を添加すると緻密なフェライ 卜焼結体が得られることがわかり，このような焼結体は 実用的見地からも興味がもたれる。したがって今後は， 弗化物の添加によってなぜこのような焼結体が得られた かを検討していくとともに，実用化の検討も進めていく つもりである。

謝 辞本報告をまとめるにあたり，名古屋大学 工学部 斎藤 肇教授に貴重なご助言とご指導をいただいた。当所にお いては, 江本正之, 黑川 進, 関 道治, 鴨下源一, 一八瀬幸 雄の各博士に種々のご援助とご指導をいただいた。 また，佐久 間修二氏には実験にご協力いただいた。ここに心から感謝の意 を表する。

\section{文献}

1）粉体粉末治金協会編, “磁性材椟” 日刊工業新聞社(1970) p. $62-66$.

2）小林成彬，鳥居道寞，日本特許 特公昭 36-12635.

3) M. Schieber, J. Appl. Phys. 35 [3] 1072-73 (1964).

4) L.H. Brixner, U.S. Pat. No. 2,962,345 (1960).

5) R. Greenhalgh, J.P. Riley, Anal. Chem. Acta 25 [2] 179-88 (1961).

6) F.J. Frere, Anal. Chem. 33 [4] 644-45 (1961).

7）日本化学会編,“化学便覧基礎編 I” 丸善 (1966) p. 11618.

(11/1/1973 受付) 